\title{
Studying the Successor Startup Enterprises-A Case Study of Quang Binh Province, Vietnam
}

\author{
Tran Tu Luc*, Le Khac Hoai Thanh, Nguyen Thi Kim Phung \\ Faculty of Economic and Tourism, Quang Binh University, Dong Hoi, Vietnam \\ Email: *tranlucqbu@gmail.com
}

How to cite this paper: Luc, T. T., Thanh, L. K. H., \& Phung, N. T. K. (2020). Studying the Successor Startup Enterprises-A Case Study of Quang Binh Province, Vietnam. Open Journal of Business and Management, 8, 1426-1438.

https://doi.org/10.4236/ojbm.2020.84091

Received: May 19, 2020

Accepted: June 16, 2020

Published: June 19, 2020

Copyright $\odot 2020$ by author(s) and Scientific Research Publishing Inc. This work is licensed under the Creative Commons Attribution International License (CC BY 4.0).

http://creativecommons.org/licenses/by/4.0/

\begin{abstract}
The paper aims to study and build a model to assess the success of startups. In Quang Binh province, Vietnam, in recent years, startup and entrepreneurship are being considered as goals and also a means to make three strategic breakthroughs, including institutions, infrastructure and human resources. With that trend, there are many new startups, young, vibrant and determined to realize their passion with intense business belief. However, there have not been many studies that assess the success and factors affecting the success of startup businesses in Quang Binh as well as in Vietnam. Therefore, the article systematizes the research in the world and in the country about the success and the factors affecting the success of startup businesses, thereby building a model to evaluate the success of the startup and be a scientific basis for researchers, investors to evaluate the success of startups. This study also makes practical contributions and the model can be used in Vietnam to increase the ability of success of startup enterprises.
\end{abstract}

\section{Keywords}

Startup, Entrepreneurship, Successful Startup, Success Prediction Model, Quang Binh Province

\section{Introduction}

Startup is a hot topic in countries around the world, which attracts the attention of businesses, investors, policymakers, scholars and researchers. Thus, there have been many researches related to startup.

In the past, there were some case studies like Lussier (1995) had designed a model to test non-financial predictors of the success and failure of young firms. Benzing et al. (2009) surveyed 139 businessmen in Ankara, Turkey to study motivations for business ownership, the factors contributing to success, and prob- 
lems of business in Turkey. Chittithaworn et al. (2011) identified factors that are affecting business success of small and medium enterprises (SMEs) in Thailand.

Recently, finding the answer for the ability to success of startup still gets the attention of many scholars. Lussier model was applied by Hyder \& Lussier (2016) on the success and failure of enterprises with the sample of 143 small businesses by regression statistical analysis. The results indicate that proper business planning, staffing, adequate funding, and partnerships are critical to the viability and success of small businesses in Pakistan. Da Silva (2016) developed a successful predictive model that can predict the success of Portuguese startups; with four explanatory variables: characteristics of founders, capital, characteristics of startups and external factors by using logistic regression.

Baidoun et al. (2018) examine the factors that lead to success or failure of a small business in the West Bank of Palestine using Lussier model. Results indicate that having adequate capital, keeping good records with financial controls, making plans and getting professional advice on how to manage the firm are the most important factors for the viability and success of small businesses.

Deb Nath, D. \& Deb Nath, S. (2019) examine the factors that lead to success or failure of small business in North East India. The results indicated ten variables support the probability of success of small businesses if they have adequate capital, keep good records and financial control, have industry experience, have management experience, have specific business plans, receive professional advice, have higher level of education, have good product/service timing, have marketing skills, and are older in age.

According to Gyimah et al. (2019) many of them are about the question why some startups succeed and others fail? The findings are inconsistency, as they have failed to clearly identify a list or model of variables that do in fact contribute to the success or failure of small businesses (2019).

An overview of the theory and practice shows that previous studies on the success/failure of startup businesses often use financial or non-financial models and model of internal and external factors. The research results show that studied factors (both financial and non-financial and both internal and external factors) have an influence on the success/failure of the business, so the current research which uses a combination of these factors is more widely used.

Quang Binh is a poor province of Vietnam, the provincial GDP per capita is one of the lowest of Vietnam, the economy is mainly based on agriculture. Startup is being considered a solution to the local economic development; however, the fear of failure greatly affects entrepreneurship. Therefore, building a model to study the success of startups to help founders and agencies has appropriate measures to promote local startups. However, in Quang Binh and in Vietnam, there has not been any specific research study on the success of startups. Thereafter, the aim of this study is to identify the significant factors responsible for success and failure of startup in Quang Binh where no similar previous study was carried out and make practical contributions to increase the ability of suc- 
cess of startup enterprises.

\section{Literature Review}

\subsection{Startup}

There is no universally accepted definition for startup, several parameters to define it have been used: age, profitability, growth metrics and other categories. Although, startups and new enterprises share some common characteristics, like age and size, they differ in essential points, namely strategy, innovation and ability to grow. There are many different views about startups. As review here are 3 views of starting a business as follows:

1) Startup is all business activities including starting a business, starting to operate a business activity, trading regardless of size. Accordingly opening a cafe is a startup; opening an online food store on Facebook is also a startup.

2) Startup is often associated with technology application, scalability and rapid growth-this form often distinguished from traditional business and small business enterprises (SMEs).

3) There are also broader understandings when considering Entrepreneurship as self-control, as the ability to create new values, thereby finding a stable job and income to support founders themselves and their family.

"Every startup is an active company that solves a problem when it's not yet clear and success is not guaranteed" said Neil Blumenthal, co-founder and CEO of Warby Parker. Startup with Adora is "When many people are involved in your company and pursue risky decisions and give up stability, in return for promises of future growth and excitement'. According to American Heritage Dictionary, startup is "the act or process of setting into operation".

From theoretical and practical research, the article defines the concept of startup for research as follows: "Startups are all businesses registering for the first time regardless of size (including small-sized enterprises, medium-sized enterprises and large-scale enterprises)".

\subsection{The Success of Startup}

The business operates with social and economic goals as well as short-term and long-term goals. Therefore, a business is considered successful when it meets its operational goals. Identifying and measuring business success can be difficult because it is a relative measure.

Success can be measured in a variety of ways and it will depend on whether the business goals can be financial or non-financial, simple predefined expectations or the founder's behavior. In 1986, Barney defined success as a measure of performance that occurs when businesses create value for their customers in a sustainable and cost-effective manner. Although, other performance measures have been used: business strategy, resources and organizational structure, processes and systems, revenue, employment growth (Hmieleski \& Baron, 2009; Chrisman et al., 1998), profits and other financially performance measures 
(Mayer-Haung et al., 2013).

Da Silva (2016) also differentiates survival and success. Survival is the minimum criteria of business success in all definitions. Survival is an absolute measure of enterprise performance that depends on the ability of the enterprise to continue to operate as a self-sustaining economic entity. The determination of a suitable period of time, after which survival is to be stated, is the most important methodological problem related to survival as a measure of business success. If the period is too short, the success measure is not demanding enough. If a too long reference period is chosen, the focus can be shifted from startups to established companies, considering the assumptions of startup definition.

Within this study, successful startups are identified as those that have been operating for over three years regardless of whether or not they change their ownership or achieve their goals. If a startup changes ownership over a four-year period and remains active, achieving its goals, it is determined to be a successful case.

\section{Data and Methodology}

\subsection{Research Model}

In order to build a model that includes factors to assess the ability of the enterprise to succeed, the study synthesizes, analyzes theories and researches related to this field. At the same time, collecting primary information through interviews with founders of some startups to determine the factors affecting the ability to succeed/fail of the business. The author proposes a research model (Figure 1 ) to evaluate the success of startup businesses including 6 groups of impact factors including: experience of founder (kinhnghiem), network of founder (moiquanhe), resources of startup (nguonluc), startup products (sanpham), external environment (moitruongbenngoai) and business environment (moitruongnganh).

The general estimating equation could be written as follows:

$$
\mathrm{TCDN}_{i}=\beta_{0}+\beta_{1} \mathrm{KN}_{i}+\beta_{2} \mathrm{MQH}_{i}+\beta_{3} \mathrm{NL}_{i}+\beta_{4} \mathrm{SP}_{i}+\beta_{5} \mathrm{MTN}_{i}+\beta_{6} \mathrm{MTK}_{i}+e_{i}
$$

where

TCDN: represents the dependent variable (the success of startup-TCDN); $\mathrm{KN}_{i}, \mathrm{MQH}_{i}, \mathrm{NL}_{i}, \mathrm{SP}_{i}, \mathrm{MTN}_{i}, \mathrm{MTKD}_{i}$ : represent the independent variables; $\beta_{0}, \beta_{1}, \beta_{2}, \beta_{k}$ : represent the regression coefficients; $e_{i}$ : represents the error of the model, the disturbance term.

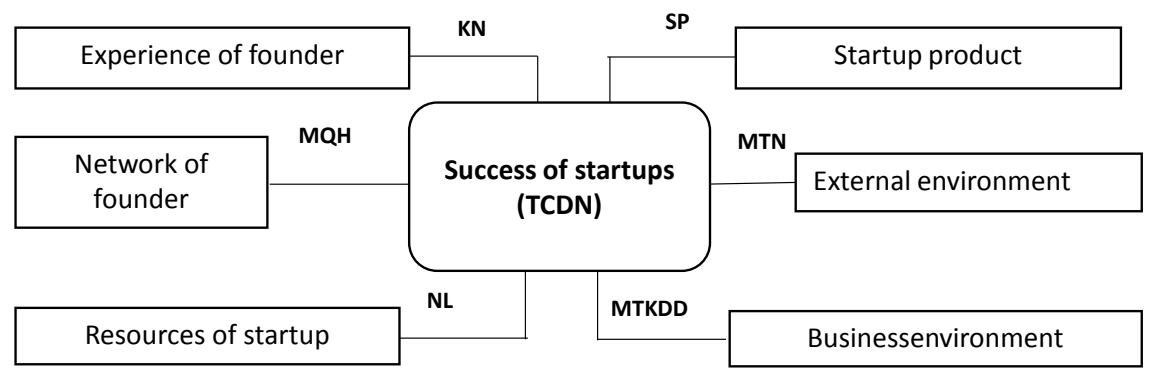

Figure 1. Proposed research model. Source: Authors (2019). 


\subsection{Survey Design and Selection of Scales}

The questions of each factor are designed based on the reference from the research of Lussier (1995), Benzing et al. (2009), Lussier and Hyder (2016), Da Silva (2016). After preliminary research, conducting trial interviews with 30 founders, the factors in the model are showed in Table 1. Specific sets of observations measured on a 5-point Likert (1-strongly disagree; 2-disagree; 3-disagree; 4-agree; 5-strongly agree). After the preliminary study, the study made specific adjustments and additions via Table 1 .

Table 1. A scale of factors affecting the success of a startup.

\begin{tabular}{|c|c|}
\hline Variable code & Observed variables \\
\hline \multicolumn{2}{|c|}{ Experience of founder (KNNKN/KN) } \\
\hline KN1 & Industry experience \\
\hline KN2 & Management experience \\
\hline KN3 & Marketing experience \\
\hline KN4 & Previous start-up experience \\
\hline KN5 & Family experience \\
\hline \multicolumn{2}{|c|}{ Network of founder (MQHNKN/MQH) } \\
\hline MQH1 & Having relationships with partners in the same industry \\
\hline MQH2 & Get support from relatives \\
\hline MQH3 & Relationship with public administrative agencies \\
\hline MQH4 & Take advantage of social relationships from family's relations \\
\hline \multicolumn{2}{|c|}{ Resources of startup (NLTCKN/NL) } \\
\hline NL1 & Sufficient capital \\
\hline NL2 & Modern facilities, equipment and technology \\
\hline NL3 & Having enough and responsible human resources \\
\hline NL4 & Industrial consultants \\
\hline \multicolumn{2}{|c|}{ Startup product (SPKN/SP) } \\
\hline SP1 & Differentiated products in the market \\
\hline SP2 & Products use new materials \\
\hline SP3 & Products meet the needs of customers \\
\hline SP4 & Typical local products \\
\hline \multicolumn{2}{|c|}{ External environment (MTBN/MTN) } \\
\hline MTN1 & Get support from a startup community \\
\hline MTN2 & $\begin{array}{l}\text { Stable political situation, the laws are clearly defined, the government performs } \\
\text { well the role of regulating the macro economy }\end{array}$ \\
\hline MTN3 & High growth rate. Interest rates and tax rates are suitable for the business \\
\hline MTN4 & $\begin{array}{l}\text { The introduction and development of new technologies create favorable } \\
\text { conditions for businesses and force them to innovate technologies to enhance } \\
\text { their competitiveness }\end{array}$ \\
\hline
\end{tabular}




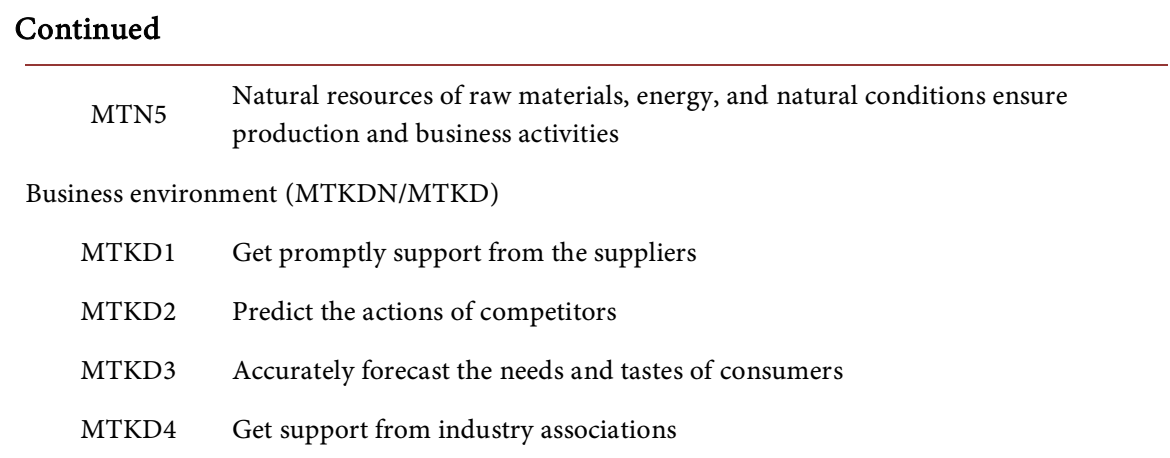

Source: Authors (2019).

\subsection{Select the Sample and Data Collection Method}

The measurement model consists of 26 observed variables, according to the minimum rule of Bentler \& Chou (1987) for a measurement variable: $5 \times 3=15$ samples, so the initial number of calculated samples is $390(26 \times 15)$. The study has determined that the number of survey samples from 390 or more is a reliable, in order to ensure this sample size, the author issues 450 questionnaires in Quang Binh province. After removing the response that does not meet the requirements and cleaning the data, the remaining samples are 390.

\subsection{Methods of Data Analysis}

The study uses SPSS 16.0 software to analysis with following steps:

- Descriptive statistical method: Using frequency tables to classify the sample according to classification variables.

- Test the reliability of the scale: To test the reliability of the assumptions scale research, common methods used Cronbach's alpha coefficient. The Cronbach's Alpha coefficient shows the intrinsic consistency of the observed variables in the factor. The formula for Cronbach's alpha coefficient is: $\alpha=$ $N p /[1+p(N-1)]$. The selection criteria in this study are the Cronbach's Alpha coefficient greater than or equal to 0.6 is acceptable. Cronbach's alpha calculations help analysts eliminate inappropriate variables and limit spam variables during research.

- Explore factor analysis (EFA): Use discovery factor analysis (EFA) to test the convergence of conceptual component variables. Variables with a single correlation coefficient between variables and factor loading less than 0.5 will be excluded; Use discovery factor analysis (CFA) to shrink and summarize data. Standards when analyzing factors discover coefficient Myer-Kaiser-Olkin (KMO) measure the adequacy of the sample and the significant meaning of accreditation Bartlett. KMO has an appropriate value within $[0.5 ; 1]$.

- Confirming factor analysis (CFA): To measure the suitability of the model with market information, this study uses Chi-square (CMIN); Chi-square adjusted according to degrees of freedom (CMIN/df); Comparative Fit Index (CFI). Tucker \& Lewis Index (TLI); Root Mean Square Error Approximation 
(RMSEA). The model is considered suitable for market data when Chi-square test has $P$-value $<0.05$. The CFA method is used to reaffirm the univariate, multivariate, convergent and distinguishing values.

Also using the method of testing the suitability of the theoretical model by SEM; model estimation test by BOOSTRAP analysis and structural regression testing.

\section{Results and Discussion}

\subsection{Sample Characteristics}

The sample size is 390, with a 5-point Likert scale results in Skewness and Kurtosis values of the distribution variables in the range $[-1,+1]$, so the distribution is close to the standard and the estimation method amount of ML (Maximum Likelihood) is accepted for use. With a Likert 5 interval (from 1: strongly disagree to 5: strongly agree). Regarding to age, the survey samples have an unequal division among age groups, people surveyed are most concentrated in the age group from 25 to 36 years old, accounting for $63.7 \%$ and the lowest is the group of people under 25 years old accounting for $1.3 \%$. $60.5 \%$ of entrepreneurs surveyed identified themselves as male, and $39.5 \%$ as female. Regarding to marital status, the majority are married, accounting for $69.4 \%$ and single accounting for $30.6 \%$. Regarding to education, $51.6 \%$ of the respondents completed college and university, $5.1 \%$ of respondents did not graduated from high school.

\subsection{Test the Reliability of the Scale}

Conducting the reliability test of the scale shows that External environment is measured by 5 factors from MTN1 - MTN5 with Cronbach's Alpha coefficient = $0.773>0.6$, Coefficient of correlation of total variables $>0.4$ except MTN5 variable has a correlation coefficient of total $0.163<0.4$. Cronbach Alpha coefficient if MTN5 is deleted $=0.853$, thus MTN5 should be excluded from the scale. After eliminating MTN5 variable, Cronbach Alpha coefficient $>0.6$, the observed variables have a Coefficient of correlation of total variables $>0.4$ so the scale achieves reliability for the next study.

Business environment is measured by 4 factors from MTKD1 - MTKD4 with Cronbach's Alpha coefficient $=0.647>0.6$, Coefficient of correlation of total variables $>0.4$ except variable MTKD4 with variable correlation coefficient is 0.256 $<0.4$. Cronbach Alpha coefficient if the variable MTKD4is deleted $=0.703$, thus, MTKD4 should be excluded from the scale. The scale of business environment includes variables MTKD1, MTKD2, MTKD3 with Cronbach's Alpha coefficient $>0.6$, observed variables with Coefficient of correlation of total variables $>$ 0.4 , so the scale achieves reliability for the next study.

Thus, the results of the reliability analysis of the scale have removed two variables (because the coefficient correlation to the total variable is less than 0.4 ), the remaining 24 variables are included in the EFA analysis, the scale compo- 
nents have Cronbach's alpha coefficient $>0.6$.

\subsection{Explore Factor Analysis}

Using factor analysis by SPSS 16.0 for EFA results as follows: MTKD3 component with a Factor Loading less than 0.5 should be excluded. The business environment scale has the remaining 2 observed variables, MTKD1 and MTKD2.

\subsection{Confirming Factor Analysis (CFA)}

The results of using AMOS 20 software to conduct CFA analysis test the suitability of the theoretical model and test the hypotheses as follows.

\subsubsection{Test the Suitability of Model}

The results of CFA test by AMOS 20 software (Figure 2) follow the principle of adjusting relationships with MI $>4$ (MI-Modification Indice, which is the adjustment coefficient corresponding to the change of $\chi^{2}$ on a degree of freedom) but this adjustment must ensure the theoretical basis and implies the practical meaning. After making the adjustment, the CFA results show that the indicators evaluating the suitability of model have been significantly improved as shown below $\left(\chi^{2} / \mathrm{df}=1.596\right.$; GFI $=0.884$; TLI $=0.933$; CFI $=0.943$; $\left.\mathrm{RMSEA}=0.052\right)$. Therefore, this model is suitable for the survey data.

\subsubsection{Test Estimation Model by BOOTSTRAP Analysis}

To assess the sustainability of model, Bootstrap analysis is used. This is an alternative sampling method with an incremental sampling $(\mathrm{N}=390)$, in which the initial sample plays a crowd role (Schumacker \& Lomax, 1996). The number of replicate samples in the study was $B=1500$ times, the estimated results with $B$ times from $\mathrm{N}$ samples were averaged and this value tended to be close to the overall estimate. The bias of the estimate (bias) and its standard deviation are small and stable value which allows it to be concluded that the ML estimates applied in the model are reliable and could be used for further hypothesis tests.

\subsection{Testing Regression Structure Model}

As results of the analysis show in Table 2, all observed variables are significant in the scale of Standardized Regression Weights which are greater than 0.5.

Test of convergent validity, discriminant validity and reliability: As can be seen from Table 3, all CR values are greater than 0.7 so the reliability of the scale is guaranteed. All AVE values are greater than 0.5 so convergent validity is guaranteed. All MSV values are smaller than AVE, SQRTAVE values are larger than all Inter-Construct Correlations so that discriminant validity is guaranteed.

\subsection{ANOVA Analysis}

Marital status: With Sig. $=0.648(>0.05)$ so there is no difference in the success of a startup when the entrepreneur is married. 


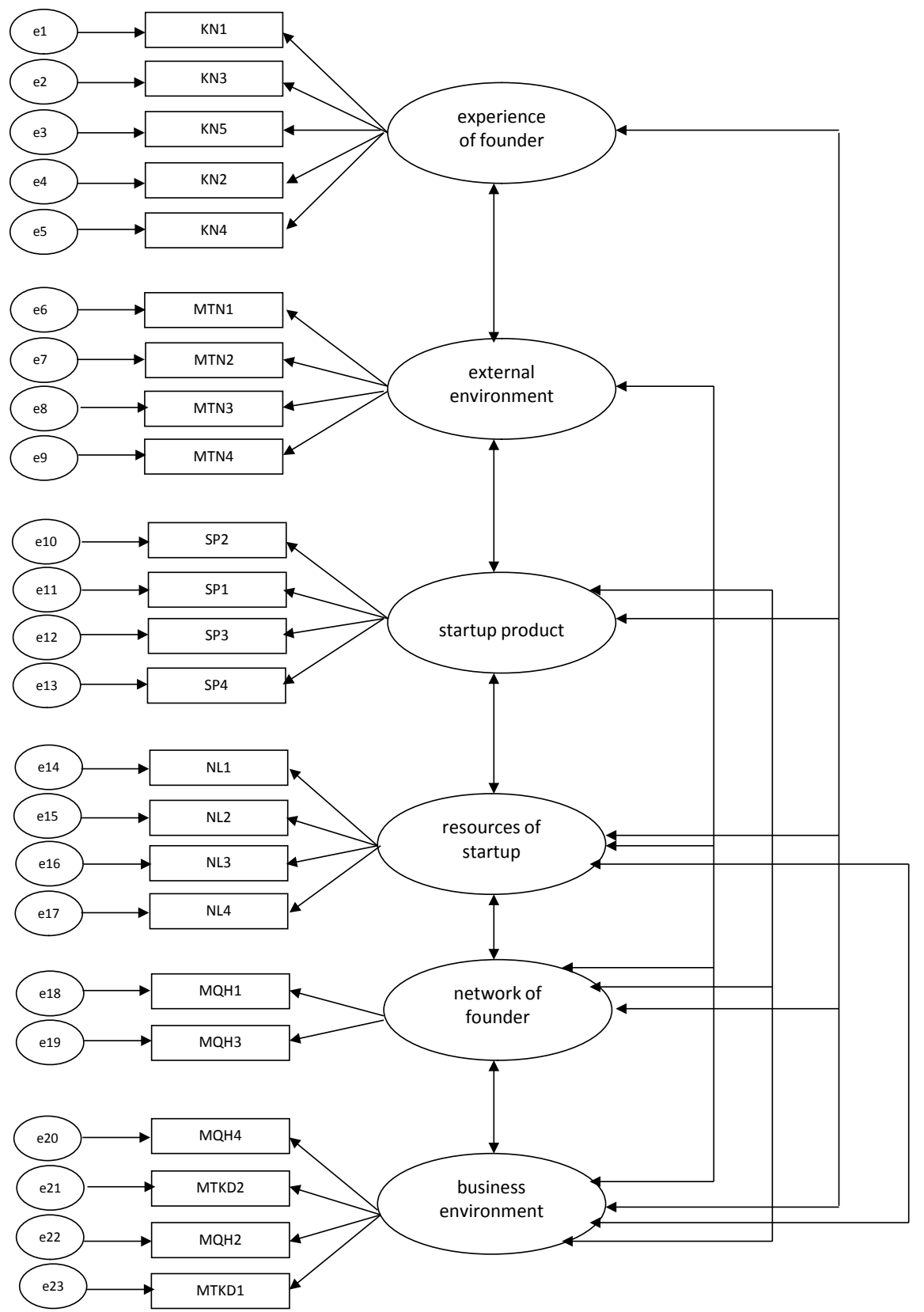

Figure 2. Standardized confirmatory factor analysis (CFA). Source: Survey data (2019).

Table 2. Results of confirmatory factor analysis.

\begin{tabular}{|c|c|c|c|c|c|c|c|}
\hline \multicolumn{7}{|c|}{ Estimate } & \multirow{2}{*}{$\begin{array}{c}\text { Estimate } \\
0.719\end{array}$} \\
\hline KN1 & $<--$ & experience of founder & 0.792 & SP4 & $<--$ & startup product & \\
\hline KN3 & $<--$ & experience of founder & 0.753 & NL1 & $<--$ & resources of startup & 0.729 \\
\hline KN5 & $<--$ & experience of founder & 0.751 & NL2 & $<--$ & resources of startup & 0.633 \\
\hline $\mathrm{KN} 2$ & $<--$ & experience of founder & 0.666 & NL3 & $<--$ & resources of startup & 0.708 \\
\hline KN4 & $<--$ & experience of founder & 0.655 & NL4 & $<--$ & resources of startup & 0.661 \\
\hline MTN1 & $<--$ & external environment & 0.828 & MQH1 & $<--$ & network of founder & 0.775 \\
\hline
\end{tabular}




\begin{tabular}{|c|c|c|c|c|c|c|}
\hline \multicolumn{7}{|c|}{ Continued } \\
\hline MTN2 & $<--$ & external environment & 0.780 & MQH3 & $<--$ network of founder & 0.783 \\
\hline MTN3 & $<--$ & external environment & 0.764 & MQH4 & $<--\quad$ network of founder & 0.738 \\
\hline MTN4 & $<--$ & external environment & 0.722 & MQH2 & $<--\quad$ network of founder & 0.673 \\
\hline SP2 & $<--$ & startup product & 0.751 & MTKD1 & $<--$ business environment & 0.708 \\
\hline SP1 & $<--$ & startup product & 0.772 & MTKD2 & $<--$ business environment & 0.710 \\
\hline SP3 & $<--$ & startup product & 0.758 & & & \\
\hline
\end{tabular}

Source: Survey data (2019).

Table 3. Test results of convergent validity, discriminant validity and reliability.

\begin{tabular}{ccccc}
\hline & CR & AVE & MSV & ASV \\
\hline network of founder & 0.755 & 0.607 & 0.428 & 0.289 \\
experience of founder & 0.847 & 0.526 & 0.444 & 0.319 \\
external environment & 0.857 & 0.600 & 0.420 & 0.328 \\
startup product & 0.837 & 0.563 & 0.552 & 0.370 \\
resources of startup & 0.778 & 0.568 & 0.554 & 0.283 \\
business environment & 0.800 & 0.501 & 0.452 & 0.460 \\
\hline
\end{tabular}

Source: Survey data (2019).

Gender: Sig. $=0.023(<0.05)$, there should be a difference in the success of startup businesses between different gender of entrepreneur.

Age: Sig. $=0.23(<0.05)$, there should be a difference in the success of startup businesses between different age group.

Education: Sig. $=0.544(>0.05)$ so there is no difference in the success of startup businesses between different education levels.

\subsection{Discussion}

The paper aims to research and build a model to evaluate the success of startups. The paper builds a theoretical model and practical research in Quang Binh province on factors affecting the success of startup businesses. Research data was collected through a survey of 450 entrepreneurs and collected 390 valid samples. The scales for factors affecting the success of startups are built on a theoretical basis and are developed to suit the context of economic conditions in Quang Binh province, Vietnam.

The results of the OLS regression model (Table 4) show that all six components have a positive impact on the success of startups, of which experience of founder is the largest (0.402), external environment (0.235), business environment (0.161), network of founder (0.128), startup product (0.117), and resources of startup (0.109). The overall regression model is rewritten as follows:

$$
\begin{aligned}
\mathrm{TCDN}= & 2.37+0.402 \mathrm{KN}+0.235 \mathrm{MTN}+0.161 \mathrm{MTKD}+0.128 \mathrm{MQH} \\
& +0.117 \mathrm{SP}+0.109 \mathrm{NL}+e_{i}
\end{aligned}
$$


Table 4. Results of regression analysis in SPSS.

\begin{tabular}{|c|c|c|c|c|c|c|c|c|}
\hline \multicolumn{2}{|r|}{ Model } & $\mathrm{R}$ & \multicolumn{2}{|c|}{ R Square } & \multicolumn{2}{|c|}{ justed R Square } & \multicolumn{2}{|c|}{ Std. Error of the Estimate } \\
\hline \multicolumn{2}{|r|}{1} & $0.830^{\mathrm{a}}$ & \multicolumn{2}{|c|}{0.688} & \multicolumn{2}{|l|}{0.672} & \multicolumn{2}{|c|}{0.13562} \\
\hline & \multicolumn{2}{|l|}{ Model } & Sum of Squares & df & \multicolumn{2}{|c|}{ Mean Square } & F & Sig. \\
\hline & \multicolumn{2}{|c|}{ Regression } & 154.377 & 6 & \multicolumn{2}{|c|}{25.729} & $1.399 \mathrm{E} 3$ & $0.000^{\mathrm{a}}$ \\
\hline \multirow[t]{2}{*}{1} & \multicolumn{2}{|c|}{ Residual } & 7.044 & 384 & \multicolumn{2}{|c|}{0.018} & & \\
\hline & \multicolumn{2}{|c|}{ Total } & 161.421 & 390 & & & & \\
\hline & \multirow[t]{2}{*}{ Model } & \multicolumn{2}{|c|}{$\begin{array}{l}\text { Unstandardized } \\
\text { Coefficients }\end{array}$} & $\begin{array}{c}\text { Standardized } \\
\text { Coefficients }\end{array}$ & \multirow[t]{2}{*}{$\mathrm{t}$} & \multirow{2}{*}{ Sig. } & \multicolumn{2}{|c|}{ Collinearity Statistics } \\
\hline & & B & Std. Error & Beta & & & Tolerance & VIF \\
\hline & (Constant) & 2.370 & 2.047 & & 3.510 & 0.002 & & \\
\hline & $\mathrm{KN}$ & 0.402 & 0.013 & 0.612 & 6.117 & 0.007 & 0.569 & 1.759 \\
\hline & MTN & 0.235 & 0.017 & 0.402 & 7.318 & 0.000 & 0.321 & 1.114 \\
\hline \multirow[t]{4}{*}{1} & MTKD & 0.161 & 0.016 & 0.757 & 2.727 & 0.000 & 0.618 & 1.619 \\
\hline & $\mathrm{MQH}$ & 0.128 & 0.012 & 0.267 & 6.402 & 0.008 & 0.602 & 1.660 \\
\hline & SP & 0.117 & 0.013 & 0.273 & 1.787 & 0.000 & 0.307 & 1.259 \\
\hline & NL & 0.109 & 0.015 & 0.239 & 1.573 & 0.006 & 0.427 & 1.340 \\
\hline
\end{tabular}

Source: Survey data (2019).

\section{Conclusion}

We research and build a model to evaluate the success of startup that plays an important role in the formation of startups, managing startups to success in Quang Binh and in Vietnam. The paper has systematized the theoretical basis and research to evaluate the success of startups; identify the factors that affect the success of startups and build a model to evaluate the success of startups, and test the research hypotheses about the relationship between those factors. The results of assessing factors affect the success of startups in Quang Binh show that there are 6 factors that influence the success of startups: experience of founder, external environment, business environment, network of founder, startup products and resources of startup. The research results show that entrepreneur's experience has the greatest impact on the success of startup businesses in Quang Binh province, this is similar to the research results of other studies. Human resources and capital have been assessed by previous studies as having a great influence on the success/failure of startups, however, for the case study of Quang Binh province, resources of startup still have an impact on the success of startup, but the lowest. With the high rate of startup failure in Vietnam, results of this study provide a list of variables that contribute to the success of startup. Firms that focus on these important factors will increase their odds of success. Thus, to improve the operational efficiency of startups requires business managers to 
regularly accumulate their own experience. Government agencies and policy makers should take measures to improve their capacity, train human resources and provide legal support for startup. The ANOVA analysis also provides some information, such as the difference in startup success by age and gender; there is no difference in the success of start-ups in terms of marriage status and education level; this is very useful for managers, policy makers in the future.

\section{Conflicts of Interest}

The authors declare no conflicts of interest regarding the publication of this paper.

\section{References}

Baidoun, S. D., Lussier, R. N., Burbar, M., \& Awashra, S. (2018). Prediction Model of Business Success or Failure for Palestinian Small Enterprises in the West Bank. Journal of Entrepreneurship in Emerging Economies, 10, 60-80. https://doi.org/10.1108/JEEE-02-2017-0013

Barney, J. B. (1986). Organization Culture: Can It Be a Source of Sustained Competitive Advantage? Academy of Management Review, 11, 656-665. https://doi.org/10.5465/amr.1986.4306261

Bentler, P. M., \& Chou, C.-P. (1987). Practical Issues in Structural Modeling. Sociological Methods and Research, 16, 78-117. https://doi.org/10.1177/0049124187016001004

Benzing, C., Chu, H. M., \& Kara, O. (2009). Entrepreneurs in Turkey: A Factor Analysis of Motivations, Success Factors, and Problems. Journal of Small Business Management, 47, 58-91. https://doi.org/10.1111/j.1540-627X.2008.00262.x

Chittithaworn, C., Islam, M. A., Keawchana, T., \& Yusuf, D. H. M. (2011). Factors Affecting Business Success of Small \& Medium Enterprises (SMEs) in Thailand. Asian Social Science, 7, 180-190.

Chrisman, J. J., Banerschmidt, A., \& Hofer, C. W. (1998). The Determinants of New Venture Performance: An Extended Model. Entrepreneurship Theory and Practice, 23, 529. https://doi.org/10.1177/104225879802300101

Da Silva, D. S. (2016). Portuguese Startups: A Success Prediction Model.

Deb Nath, D., \& Deb Nath, S. (2019). Prediction Model of Success or Failure for Small Business in North East India. Journal of Management, 6, 197-201. https://doi.org/10.34218/JOM.6.1.2019.021

Gyimah, P., Appiah, K. O., \& Lussier, R. N. (2019). Success versus Failure Prediction Model for Small Businesses in Ghana. Journal of African Business, 21, 215-234. https://doi.org/10.1080/15228916.2019.1625017

Hmieleski, K. M., \& Baron, R. A. (2009). Entrepreneurs' Optimism and New Venture Performance: A Social Cognitive Perspective. Academy of Management Journal, 52, 473-488. https://doi.org/10.5465/amj.2009.41330755

Lussier, R. N. (1995). A Nonfinancial Business Success versus Failure Prediction Model for Young Firms. Journal of Small Business Management, 33, 8-19.

Lussier, R. N., \& Hyder, S. (2016). Why Businesses Succeed or Fail: A Study on Small Businesses in Pakistan. Journal of Entrepreneurship in Emerging Economies, 8, 82-100. https://doi.org/10.1108/JEEE-03-2015-0020

Mayer-Haung, K., Read, S., Brickmann, J., Dew, N., \& Grichnik, D. (2013). Entrepre- 
T. T. Luc et al.

neurial Talent a Venture Performance: A Meta-Analytic Investigation of SME. Research Policy, 42, 1251-1273. https://doi.org/10.1016/j.respol.2013.03.001

Schumacker, E. R., \& Lomax, G. R. (1996). A Beginner's Guide to Structural Equation Modeling. Mahwah, NJ: Erlbaum. 